\title{
Editorial
}

\section{The vulnerable child}

This issue includes several papers on what we expose our children to in terms of environment and behavioural patterns.

\section{Parents}

Parental education is an important factor in affecting children's dietary patterns, as shown again here in two studies from Germany ${ }^{(1,2)}$. In a focus group study from the USA, parents from low-income schools showed that they had only basic knowledge about healthy food and got most of their nutrition information from the media ${ }^{(3)}$. These parents indicated that they would be happy to learn more about healthy eating and to participate in training sessions involving the whole family. A paper related to active commuting to school ${ }^{(4)}$ showed that in a group of Spanish adolescents, a good sleep pattern seemed positively correlated to active commuting, while having breakfast seemed to be a hindrance.

\section{Staff}

A British study showed that day-care staff in Liverpool are genuinely interested in providing good food for their children but require support in doing this, especially with respect to menu planning, cooking and management ${ }^{(5)}$. The same study also showed lack of knowledge among the staff responsible for preparing the food, and several nutritional problems with the actual food served ${ }^{(6)}$.

\section{Policy}

A study from Texas, USA ${ }^{(7)}$ showed that middle-school students' lunch intake does not meet the new Institute of Medicine recommendations. Along the same lines, lunch boxes in South Africa were shown to provide a more diverse diet than food bought in or near the school ${ }^{(8)}$. A review within the USA found a high degree of similarity across policies relating to snacks offered in US afterschool programmes ${ }^{(9)}$.

Parents and day care, school and after-school staff, the important adults around children and adolescents, carry a responsibility for providing good opportunities for the young ones to achieve healthy eating, physical activity and sleep patterns. Policies are important supportive tools in this regard, but without proper implementation they will fail to achieve the intended outcomes. Capacity building among all important adults is pivotal to ensuring the best nutrition possible.

Agneta Yngve

Editor-in-Chief

Irja Haapala

Geraldine McNeill

Marilyn Tseng

Allison Hodge

Deputy Editors

\section{References}

1. Sausenthaler S, Standl M, Buyken A et al; ; for the GINIplus and the LISAplus Study Groups (2011) Regional and socioeconomic differences in food, nutrient and supplement intake in school-age children in Germany: results from the GINIplus and the LISAplus studies. Public Health Nutr 14, 1724-1735.

2. Bau A-M, Krull S, Ernert A et al. (2011) Eating behaviour and its association with social living conditions and weight status among adolescent girls: results of the cross-sectional Berlin School Children's Cohort study. Public Health Nutr 14, 1759-1767.

3. Slusser W, Prelip M, Kinsler J et al. (2011) Challenges to parent nutrition education: a qualitative study of parents of urban children attending low-income schools. Public Health Nutr 14, 1833-1841.

4. Martínez-Gómez D, Veiga OL, Gomez-Martinez S et al.; AFINOS Study Group (2011) Behavioural correlates of active commuting to school in Spanish adolescents: the AFINOS (Physical Activity as a Preventive Measure Against Overweight, Obesity, Infections, Allergies, and Cardiovascular Disease Risk Factors in Adolescents) study. Public Health Nutr 14, 1779-1786.

5. Lloyd-Williams F, Bristow K, Capewell S et al. (2011) Young children's food in Liverpool day-care settings: a qualitative study of pre-school nutrition policy and practice. Public Health Nutr 14, 1858-1866.

6. Parker M, Lloyd-Williams F, Weston G et al. (2011) Nursery nutrition in Liverpool: an exploration of practice and nutritional analysis of food provided. Public Health Nutr 14, 1867-1875.

7. Cullen KW, Watson KB \& Dave JM (2011) Middle-school students' school lunch consumption does not meet the new Institute of Medicine's National School Lunch Program recommendations. Public Health Nutr 14, 1876-1881.

8. Abrahams Z, de Villiers A, Steyn NP et al. (2011) What's in the lunchbox? Dietary behaviour of learners from disadvantaged schools in the Western Cape, South Africa. Public Health Nutr 14, 1752-1758.

9. Beets MW, Tilley F, Kim YW et al. (2011) Nutritional policies and standards for snacks served in after-school programmes: a review. Public Health Nutr 14, 1882-1890. 